\title{
Patient outcomes: The only size that eventually matters in dealing with colonic neoplasia
}

We read with great interest the editorial by Pioche et al. on overutilizing surgery to resect benign colorectal lesions [1] We strongly agree that referral to either surgery or endoscopic intervention is a multifactorial/dimensional process that has to be well-orchestrated and executed for optimal outcomes. In fact, the chosen methods often reflect tradition and availability rather than the optimal balance between best outcome, patient convenience, and side effects. We hope that multidisciplinary educational tutors and on-the-spot endoscopic meetings will become available soon, with the advent of artificial intelligence and tools for real-time consultations such as the EndoConf [2]. To confirm or stage benign/malignant is a complex matte. The question one should ask is, "What is the prognostic advantage of those who have a 'complete resection' after endoscopic submucosal dissection (ESD) compared to those who have a primary surgical resection?" To our knowledge, the answer is none [3]. To date, there is limited European expertise in the resection of early malignant lesions with ESD. Conversely, a right hemicolectomy is neither a complex nor a major operation and the complication rate after right hemicolectomy is not high [4].

However, with all the intricacies involved in what is next, we should never lose our primary focus or overinterpret our understanding of what the patient wants. For sure, a great deal of pressure is brought to bear on clinicians to deliver precise and individual care for all, which remains a utopian view. The reasons that goal cannot be achieved are not due, but simply due to failure of good and straightforward decisions taken one step at a time. Very few patients would mind undergoing a repeat (reassessment) colonoscopy, but this should not steer us away from the main aim, that is, to get it right and get it right the first time. The pan-European explosion in co- lonoscopy procedures has led to "fast track" education of young doctors to become qualified endoscopists [5]. This may explain the lack of support and essential skills at the EU-wide level, as well as for training in complex procedures, such as ESD. Our goal should be not to lobby further for this or the other approach but to find ways to intensify the collaboration between gastroenterologists and surgeons in open-minded, multispecialty-inclusive units geared to the task of dealing with complex cases. In a proper collaborative environment, we could have access to many techniques, such as endoscopic mucosal resection, ESD, TEM, endoscopic full-thickness resection, hybrid techniques, and hemicolectomies. For example, the preoperative staging with endoscopic ultrasound of early rectal cancers $\mathrm{T} 1 \mathrm{sm} 1, \mathrm{sm} 2$ and sm3 has low accuracy with a risk of under staging in around $15 \%$ to $20 \%$ of patients. The optimal treatment is to offer completion surgery if pathology reveals that a more advanced cancer has been resected than what was believed to be T1 sm 1 disease. The past errors with too much surgery should not be followed by a new era with too much non-evidencebased therapeutic endoscopy; after all, the surgeons are the ones to deal with the completion procedures and sometimes hybrid techniques, if indicated.

\section{Competing interests}

AK is consultant for jinshan. He is director of iCERV Ltd and cofounder of AJM Medicaps Ltd. He has received a GivenImaging LtdESGE grant, and material support for clinical research from SynMed/Intromedic. In the last ten years, he has received honoraria \& lecture fees from Jinshan, Dr FalkPharma UK and Ferring. He has also received educational travel support from Aquilant, Jinshan, $\mathrm{Dr}$ FalkPharma, Almirall, Ferring, and has participated in advisory board meetings for Tillots, Ankon, and Dr FalkPharmaUK.
The authors

Thomas Bjørsum-Meyer ${ }^{1,2}$, Anastasious Koulaouzidis ${ }^{3}$, Gunnar Baatrup ${ }^{1,2}$

1 Department of Surgery, Odense University Hospital, Denmark

2 Department of Clinical Research, University of Southern Denmark, Denmark

3 Department of Social Medicine \& Public Health, Pomeranian Medical University, Szczecin, Poland

Corresponding author

Thomas Bjørsum-Meyer

Odense Universitetshospital - Department of Surgery, Winsløwsvej 4, Odense 5000, Denmark

Fax: +65413035

thomas.bjoersum-Meyer@rsyd.dk

\section{References}

[1] Pioche M, Cotte E, Hassan C. Overutilization of surgery for the resection of benign colorectal lesions: the hidden reasons for inappropriate referral! Endoscopy International Open 2021; 09: E713-E715

[2] Deding UAH, Buch N, Koulaouzidis A et al. EndoConf: real-time video consultation during endoscopy; telemedicine in endoscopy at its best. Endosc Int Open 2021; 09: E1847-E1851

[3] Silva GL, de Moura EG, Bernardo WM et al. Endoscopic versus surgical resection for early colorectal cancer-a systematic review and meta-analysis. J Gastrointest Oncol 2016; 7: 326-335

[4] Schwenk W, Haase O, Neudecker J et al. Short term benefits for laparoscopic colorectal resection. Cochrane Database Syst Review 2005; 3: CD003145

[5] Comas M, Mendivil ], Andreu M et al. LongTerm prediction of the demand of colonoscopies generated by a populationbased colorectal cancer screening program. PLoS One 2016; 11: e0164666 


\section{Bibliography}

Endosc Int Open 2021; 09: 1843-1844

DOI 10.1055/a-1591-0593

ISSN 2364-3722

(c) 2021. The Author(s).

This is an open access article published by Thieme under the terms of the Creative Commons Attribution-NonDerivativeNonCommercial License, permitting copying and reproduction so long as the original work is given appropriate credit. Contents may not be used for commercial purposes, or adapted, remixed, transformed or built upon. (https:// creativecommons.org/licenses/by-nc-nd/4.0/)

Georg Thieme Verlag KG, Rüdigerstraße 14,

70469 Stuttgart, Germany

\section{다 (i) $(5)$}

